\title{
A IMPORTÂNCIA DAS ANALISES DAS DEMONSTRAÇÕES NO PROCESSO DECISÓRIO
}

Irene Caires da Silva, Sandra Cristina Pelegrini Giacomelli

Universidade do Oeste Paulista - UNOESTE, Curso de Ciências Contábeis, Presidente Prudente, SP. E-mail: irene@unoeste.br

\section{RESUMO}

O cenário globalizado e dinâmico exige cada vez mais das empresas que querem manter-se competitivas e solidificadas no mercado. Para isso os gestores e administradores devem lançar mão de técnicas e recursos para se consolidarem. Uma grande ferramenta à disposição dos gestores é a análise contábil e financeira das principais demonstrações elaboradas pela empresa. Nestes relatórios são evidenciados todos os atos e resultados. Seus índices serão capazes de indicar as melhores ações para garantia do sucesso. Neste sentido, este estudo tem como objetivo identificar os relatórios mais utilizados nas analises contábeis e financeiras, e quais as dificuldades encontradas pela organização no processo de tomada de decisão. Esta pesquisa é de caráter exploratório, do tipo bibliográfico. Conclui-se que, utilizando as ferramentas contábeis, através de análises detalhadas, obtem-se um precioso indicador de como planejar e atuar, para garantir um desempenho que atenda aos anseios das organizações.

Palavras-chave: Contabilidade Gerencial. Demonstrações Contábeis. Analises.

\section{THE IMPORTANCE OF ANALYSIS OF STATEMENTS IN DECISION-MAKING}

\begin{abstract}
The globalized and dynamic environment increasingly demands of companies that want to remain competitive and solidified in the market. For that managers and administrators should make use of techniques and resources to consolidate. A great tool available to managers is the accounting and financial analysis of the key statements prepared by the company. These reports are evidenced all actions and results. Its contents will be able to identify the best stocks to guarantee success. Thus, this study aims to identify the most commonly used reports in accounting and financial analysis, and that the difficulties encountered by the organization in the decision-making process. This research is exploratory, the bibliographical. In conclusion, using the accounting tools, through detailed analysis, we obtain a valuable indicator of how to plan and act to ensure performance that meets the aspirations of the organizations.
\end{abstract}

Keywords: Management Accounting. Accounting Statements. analyzes 


\section{INTRODUÇÃO}

A sociedade está em constante evolução propiciando um ambiente dinâmico, moderno e exigente de bens ou serviços que superem suas expectativas. As empresas precisam estar atentas aos anseios desta sociedade para se consolidarem e obterem sucesso no mercado, uma vez que, destaca-se como objetivos principais gerar retorno para os investimentos dos sócios e fortalecer suas fontes de recursos. Cabe ao administrador ficar atento às informações da empresa para saber avaliar seu desempenho e planejar metas, projetando as ações e suas consequências com visão de futuro.

Quando o desempenho não está ocorrendo conforme o planejado, algumas ações são necessárias para sanar os problemas e evitar que se tornem desafios maiores. Os gestores ou analistas dispõem de ferramentas poderosas que lhes fornecerão dados e informações claras e detalhadas sobre a vida da empresa através de relatórios contábeis precisos e confiáveis.

A partir daí, justifica-se à necessidade de conhecer as ferramentas utilizadas nas analises das demonstrações contábeis para que as organizações possam elaborar os seus planejamentos e consequentemente tomarem decisões assertivas obtendo resultados positivos e garantindo a sua permanência no mundo dos negócios.

Ao analisar uma empresa é necessário compreendê-la como um todo, conhecer seus objetivos, atividades desenvolvidas e os resultados obtidos com as ações planejadas e executadas. Faz-se necessário também entender que a empresa não está sozinha, se relaciona com o ambiente interno que envolve sua estrutura organizacional, capacidade gerencial e nível tecnológico e o ambiente externo que são os fatores de ordem política e econômica e a concorrência entre outros, sendo que todos interferem em seu desempenho (SILVA, 2012).

Para que ocorra uma ligação entre empresa e ambiente torna-se necessária uma linguagem que possibilite a comunicação entre eles, tornando claro o papel e a importância de cada um, sendo possível avaliar o seu desempenho e traçar planos estratégicos.

Desse modo, "as demonstrações proporcionam elementos que possibilitam aos empresários e administradores o planejamento e controle do patrimônio da empresa e das atividades sócias". (REIS, 2009, p.57)

As empresas são organizações jurídicas regidas por leis e normas que estabelecem diretrizes para seu funcionamento. A sociedade limitada é regida pelos artigos 1052 a 1087 do Código Civil Brasileiro e a sociedade anônima é regida pelos artigos 1088 e 1089 do referido código, pela lei 6404/76 e suas alterações. A lei 11638/07 acrescentou obrigatoriedade à empresa 
de grande porte, mesmo classificada como limitada, de elaborar demonstrações contábeis semelhantes à sociedade por ações. (SILVA, 2012).

As demonstrações contábeis são elaboradas de acordo com normas e padrões, sendo disciplinadas por leis e instituições:

O Código Civil (Lei no 10.406, de 10-1-2002, arts 1179 a 1195) trata da escrituração, de livros contábeis e de balanço, entre outros assuntos contábeis. A legislação comercial (Lei no 6.404/76 e suas alterações) trata das regras para as sociedades anônimas, incluindo procedimentos contábeis. A Comissão de Valores Mobiliários - CVM que é uma agência governamental com papel de fiscalização e regulação do mercado de capitais brasileiro, tem varias instruções para serem seguidas pelas empresas com ações negociadas em Bolsa de Valores. (SILVA, 2012, p. 48).

As empresas, de forma geral, estão obrigadas a elaborarem demonstrações contábeis ao final do exercício social. No caso das sociedades anônimas serão elaboradas as seguintes demonstrações: balanço patrimonial, demonstração dos lucros ou prejuízos acumulados, demonstração do resultado do exercício, demonstração dos fluxos de caixa e demonstração do valor adicional, devendo publicá-las. As demais elaboram o balanço patrimonial e a demonstração de resultado de exercício, sem a obrigatoriedade da publicação.

Neste contexto, se faz necessário estudar, conhecer e interpretar os relatórios contábeis que são utilizados como base da analise contábil e financeira da organização.

Iremos apresentar os relatórios mais utilizados como referência no diagnostico financeiro, sendo o balanço patrimonial, demonstração de resultado do exercício e a demonstração de fluxo de caixa.

O balanço patrimonial é a demonstração que evidencia a situação patrimonial e financeira de uma organização, mostrando de forma qualitativa e quantitativa a equação de igualdade entre os bens e direitos em relação às obrigações com terceiros em um determinado período.

Para Matarazzo (2010, p. 26):

É a demonstração que apresenta todos os bens e direitos da empresa - Ativo - assim como as obrigações - Passivo Exigível - em determinada data. A diferença entre Ativo e Passivo é chamada Patrimônio Líquido e representa o capital investido pelos proprietários da empresa, quer através de recursos trazidos de fora da empresa, quer gerados por esta em suas operações e retidos internamente.

O balanço é composto por dois grandes grupos: ativo e passivo. O ativo tem como classificação o circulante e não circulante. O circulante representa os seguintes subgrupos: as 
disponibilidades, clientes, estoque e despesas dos exercícios futuro. O Ativo Não Circulante demonstra o realizável em longo prazo e também os investimentos, imobilizado e intangível.

Já o passivo, conhecido como capital de terceiros, se subdivide em circulante que representa as dividas da empresa com vencimento inferior a um ano. A sua divisão se classifica em obrigações com terceiro, obrigações fiscais, obrigações trabalhistas e com instituições financeiras, dentre outras e o não circulante que se refere a mesmas obrigações, porém com vencimentos superiores a um ano. O patrimônio líquido também compõe o grupo do passivo por se tratar de capital próprio, ou seja, o capital social e os recursos provenientes de suas atividades operacionais. (SILVA, 2012)

A demonstração de resultado do exercício representa a apuração dos recursos obtidos através da atividade desenvolvida pela empresa em relação aos gastos necessários para a sua prática.

De acordo com Silva, (2012, p. 75), “A demonstração do resultado do exercício, conforme o próprio nome sugere, demonstra o resultado obtido pela empresa em determinado período, isto é, o lucro ou prejuízo".

Desse modo, a demonstração de resultado do exercício, utiliza-se do método dedutivo partindo do geral para o específico, através da confrontação das receitas e despesas gerando um resultado que poderá ser positivo, negativo ou nulo.

Para Matarazzo (2010, p. 30) “É uma demonstração dos aumentos e reduções causados no Patrimônio Líquido pelas operações da empresa." E continua explicando que: "Todas as receitas e despesas se acham compreendidas na Demonstração de Resultado[...] fornecendo informações significativas sobre a empresa."

Reis (2009, p. 98) nos explica que:

Esse demonstrativo mostra, em sequência lógica e ordenada, todos os fatores que influenciaram, para mais ou para menos, o resultado do período, tornando-se assim, valioso instrumento de análise econômicofinanceira e preciosa fonte de informações para tomada de decisões administrativas.

Neste contexto, esse relatório contábil de grande relevância para os usuários interno ou externo da contabilidade, para verificar o desempenho da organização em relação a lucratividade e rentabilidade, bem como o gerenciamento das contas que compõem a estrutura da demonstração sendo elas: os custos e despesas para do desenvolvimento da atividade fim.

Outro relatório de grande valia utilizada na analise é o demonstrativo de fluxo de caixa evidenciando o gerenciamento de caixa em um determinado momento, mostrando as entradas e 
as saídas de recursos financeiros. Neste relatório é utilizado o regime de caixa, obtendo informações muito importantes sobre as principais transações ocorridas na empresa e que afetam seu caixa para mais ou para menos.

Segundo Marion (2009, p. 451) "indica a origem de todo o dinheiro que entrou no Caixa, bem como a aplicação de todo o dinheiro que saiu do Caixa em determinado período, e, ainda, o resultado do Fluxo Financeiro." E Matarazzo (2010), menciona que através da DFC é possível conhecer como fluíram os recursos ao longo de um exercício: quais foram os recursos obtidos, qual a participação das transações comerciais no total de recursos gerados, como foram aplicados os novos recursos, dentre outros.

O presente artigo tem como objetivo identificar os relatórios mais utilizados nas analises contábeis e financeiras, e quais as dificuldades encontradas pela organização no processo de tomada de decisão.

\section{METOLOGIA}

Esta pesquisa, na primeira etapa é de caráter exploratório, do tipo bibliográfico, onde se buscou informações em livros, revistas especializadas, artigos científicos, dentre outros.

De acordo com Gil $(2007$,$) a pesquisa bibliografia "tem como base alguns materiais que já$ foram anteriormente elaborados, sendo os principais livros e artigos científicos".

Já na segunda etapa foi realizado um estudo através de abordagem qualitativa, tendo a pesquisa bibliográfica como instrumento de coleta de dados.

A pesquisa qualitativa não é formada por etapa engessada como as das quantitativas: aqui, a pesquisa fica a vontade para desenhar o estudo da forma que julgar mais adequada. No entanto, é importante manter em mente que a pesquisa deve apresentar uma estrutura solida e coerente capaz de receber a aprovação dos membros da comunidade cientifica. (MASCARENHAS, 2012, p.46).

O estudo realizado teve como foco identificar as informações das analises para podemos discutir os procedimentos necessários da pesquisa em questão, com uma abordagem qualitativa.

\section{RESULTADOS}

Os resultados encontrados mostram que as empresas estão preocupadas com o bom gerenciamento dos seus recursos financeiros. Neste contexto, as demonstrações contábeis se tornam indispensáveis no processo de gestão, pois a maioria dos investidores quer segurança para gerenciar seus investimentos, recorrendo aos analistas profissionais que dispõem de 
conhecimentos e recursos tecnológicos para analisar as demonstrações e as informações com eficiência.

Desse modo, as empresas necessitam de um sistema, partindo de seu banco de dados, para gerenciar suas informações de maneira organizada e de acordo com suas necessidades. As demonstrações contábeis produzidas pelo sistema e interpretadas pelos profissionais competentes, são ferramentas valiosas na comunicação entre empresa e usuários, sejam acionistas, sócios ou demais pessoas interessadas no seu desempenho e solidez.

\section{DISCUSSÃO}

A análise de uma empresa requer procedimentos complexos e organizados tecnicamente, obtidos por etapas que inicia da coleta das demonstrações contábeis e outras informações pertencentes à empresa, seguindo para a conferência dos dados obtidos se estão completos, corretos e confiáveis.

Em seguida é a fase de reclassificação das contas que fazem parte das demonstrações contábeis segundo o padrão do analista quem desenvolve a análise e organização dos demais materiais disponíveis.

Desse modo, começa o processamento das informações e emissão dos relatórios contábeis, bem como indicadores, tais como: lucratividade, estrutura e liquidez, que servirão para a fase seguinte que é o momento da análise das informações disponíveis, as tendências apresentadas pelos indicadores e as demais conclusões que possam ser extraídas.

É o momento que exige experiência, conhecimento e observação estabelecendo a finalidade da análise, tendo fatores relacionados ao que se procura obter com essa ferramenta gerencial.

Após a execução dos procedimentos detalhado acima, chega-se ao momento da conclusão da analises, que consiste em identificar, ordenar, destacar e escrever sobre as principais informações extraídas e as recomendações indicadas à empresa, segundo suas necessidades. 0 relatório precisa ser claro de forma que o cliente possa entender as conclusões obtidas e saber utilizá-lo para tomada de decisões (SILVA, 2012).

Por fim, a utilização de todos esses procedimentos, resulta em um diagnostico econômico e financeiro da organização em estudo, que servirá como norte, no momento de planejamento, execução e controle, orientando os gestores a tomarem decisões precisas para obter resultados positivos, alcançando o sucesso empresarial. 


\section{CONCLUSÃO}

Conclui-se que o sucesso da organização está atrelado a contabilidade gerencial, facilitando o empresário a definir politicas internas de como gerenciar os recursos financeiros e obter a consolidação da empresa num mercado volátil e competitivo.

É importante ressaltar que essa ferramenta trará vários benefícios às organizações, e também para a sociedade como um todo, pois ela conseguirá reduzir os preços onde o consumidor será beneficiado com as politicas competitivas adotadas pela empresa.

Embora as analises tragam todos esses benefícios ainda encontram algumas limitações, devido ao dinamismo de alguns setores produtivos do mercado e a instabilidade politica e econômica que estamos vivenciando. Assim existem informações que são disponibilizadas aos usuários, com defasagem por serem analisadas as demonstrações encerradas ao final do exercício financeiro, mas que, ao passar dos meses, não refletem mais a realidade do cenário onde estão inseridas.

Outro aspecto que causa limitação é a veracidade da informação, já que existem práticas desonestas de alguns profissionais que contribuem para a sonegação fiscal, sendo necessária uma análise criteriosa, que vai além dos dados apresentados.

As empresas que tem consciência do seu papel produzem informações fidedignas, transparentes e facilitadoras do processo de decisão, construindo uma imagem positiva frente aos investidores, clientes e sociedade em geral.

A partir das informações fidedignas extraídas dos relatórios é possível obter interpretações que darão suporte para a elaboração dos indicadores, que poderão ser baseada não somente em índices isolados, mas deverão levar em conta também os fatores externos que fogem ao controle do administrador. Neste sentido, o analista financeiro deverá apoiar em uma visão ampla das características próprias das atividades desenvolvidas pela empresa independente do segmento que atua.

Por fim, o sucesso organizacional está atrelado com o processo de gerenciamento das informações, principalmente na utilização da ferramenta analises contábil econômica e financeira, sendo um direcionar de aprimoramento no processo de gestão, facilitando a visão futura do administrador dos recursos financeiros.

\section{REFERÊNCIAS}

GIL, A. C. Como elaborar projetos de pesquisa. 4. ed. São Paulo: Atlas, 2007.

MARION, J. C. Contabilidade Empresarial. 15a Ed. São Paulo: Atlas, 2009. 
MARCONI, M. A, LAKATOS, E. M. Fundamentos de metodologia científica. $7^{\circ}$. Ed. São Paulo: Atlas, 2010.

MASCARENHAS, S. A. Metodologia Científica. 1. Ed. São Paulo: Pearson Education do Brasil, 2012. Disponível em http: // unoeste.br3.digitalpages.com.br/users/publications/9788564. Acesso: 18 de agosto de 2015.

MATARAZZO, D. C. Análise Financeira de Balanços: Abordagem Gerencial. 7ạ Ed. São Paulo: Atlas, 2010.

REIS, A. C. R. Demonstrações Contábeis: Estrutura e Analises. 3 a Ed. São Paulo: Saraiva, 2009

SILVA, J. A. Análise Financeira das Empresas. 11a Ed. São Paulo: Atlas, 2012. 